\title{
Kajian Pengelolaan Limbah Padat Peternakan Sapi Simantri Berbasis 2R (Reduce dan Recycle) di Kecamatan Seririt, Kabupaten Buleleng
}

\author{
Gde Prima Tangkas dan Yulinah Trihadiningrum \\ Jurusan Teknik Lingkungan, Fakultas Teknik Sipil dan Perencanaan, Institut Teknologi Sepuluh \\ Nopember (ITS) \\ Jl. Arief Rahman Hakim, Surabaya 60111 Indonesia \\ e-mail: trihadiningrum@gmail.com
}

\begin{abstract}
Abstrak-Simantri atau Sistem Pertanian Terintegrasi merupakan sebuah program Pemerintah Provinsi Bali yang mengintegrasikan kegiatan pertanian dan peternakan. Pengelolaan limbah padat di peternakan sapi Simantri Kecamatan Seririt yakni pengolahan biogas dan pembuatan kompos belum berlangsung optimal. Tujuan dari penelitian ini adalah menentukan laju timbulan dan komposisi limbah padat peternakan sapi Simantri, mengevaluasi pengelolaan limbah padat eksisting. Tujuan lainnya yaitu menentukan strategi penerapan teknologi pengolahan biogas dan kompos berdasarkan analisis SWOT. Pada penelitian ini dilakukan pengklasifikasian berdasarkan peternakan yang pengolahan biogasnya masih beroperasi, pengolahan komposnya masih beroperasi dan peternakan yang pengolahan biogas dan komposnya tidak beroperasi. Pengukuran laju timbulan limbah padat berdasarkan SNI 19-3964-1994 dan analisis mass balance limbah padat. Instrumen kuisioner digunakan pada penelitian ini untuk mendapatkan informasi pengelolaan limbah padat eksisting, permasalahan, dan penilaian SWOT (Strength, Weakness, Opportunity, dan Threats). Sehingga diperoleh teknologi pengelolaan limbah padat berbasis $2 R$ yang dapat diterapkan. Total laju timbulan limbah padat peternakan sapi Simantri Kecamatan Seririt yaitu 2371,40 kg/hari dengan komposisi 303,88 kg sisa pakan/hari dan 2067,52 kg kotoran sapi/hari. Peternakan Sapi Simantri Kecamatan Seririt yang masih melakukan pengelolaan limbah padat sebanyak 53,84 \% atau 7 peternakan. Sedangkan, yang tidak melakukan pengelolaan limbah padat sebanyak 46,16\% atau 6 peternakan. Strategi penerapan teknologi untuk pengolahan limbah padat peternakan dari hasil analisis SWOT yaitu dengan melakukan pengolahan biogas dan pembuatan kompos dengan intensif dan melakukan inovasi dalam teknologi pengolahan biogas dan kompos.
\end{abstract}

Kata Kunci-2R, biogas, kompos, laju timbulan, simantri

\section{PENDAHULUAN}

$\mathrm{L}$ IMBAH peternakan merupakan sumber daya yang sangat $\omega_{\text {potensial untuk dimanfaatkan sebagai bahan baku biogas }}$ dan kompos [1]. Biogas merupakan campuran gas yang dihasilkan dari proses perombakan kotoran ternak sebagai bahan organik oleh mikroorganisme dalam kondisi tanpa oksigen atau proses anaerobik [2]. Teknologi umum yang digunakan untuk memperoleh biogas yakni dengan fermentasi kotoran ternak menggunakan anaerobik digester [3]. Digester biogas yang banyak digunakan diantaranya jenis kubah tetap (fixed-dome), drum mengambang (floating drum) dan reaktor balon [4]. Produktivitas biogas yang dihasilkan dari kotoran ternak sapi yakni $0,24 \mathrm{~m}^{3}$ biogas $/ \mathrm{kg}$ kotoran dan $0,20-0,30 \mathrm{~m}^{3}$ gas metana/kg VS (Volatile Solid) [5]-[6].

Kompos merupakan pupuk organik yang berasal dari sisa tanaman dan kotoran hewan yang telah mengalami proses dekomposisi atau pelapukan [7]-[8]. Selama proses pengomposan, mikroorganisme berkembang dan melepaskan gas karbon dioksida, air, produk organik lain serta energi. Beberapa energi digunakan untuk metabolisme dan sisanya dikeluarkan dalam bentuk panas. Pada saat suplai makanan habis, pertumbuhan mikroba dan pembentukan panas menurun dan akan dihasilkan bahan humus yang disebut kompos [9]. Pada umumnya metode atau teknologi pengomposan yaitu Static Piles, Windrow Composting, Passively Aerated Windrows, Forced Aeration Static Piles, Enclosed Composting dan Vermicomposting [10].

Sistem Pertanian Terintegrasi atau Simantri berorientasi pada usaha pertanian dan peternakan tanpa limbah (zero waste) dengan menghasilkan $4 \mathrm{~F}$ (food, feed, fertilizer dan fuel). Kegiatan utamanya adalah integrasi budidaya tanaman dan ternak, limbah tanaman diolah untuk pakan ternak dan cadangan pakan pada musim kemarau. Selain itu, limbah padat ternak (feses) diolah menjadi biogas dan pupuk organik [11][12].

Program Simantri di Kecamatan Seririt pada tahun 2015 terdapat 13 peternakan sapi Simantri yang tersebar di 11 Desa. Pengelolaan limbah padat yang dilakukan yakni dengan prinsip pengurangan limbah padat yaitu melaksanakan 2R (Reduce dan Recycle). Pengukuran laju timbulan limbah padat belum pernah dilakukan di peternakan sapi Simantri Kecamatan Seririt. Selain itu, kondisi pengelolaan limbah padat yang dilakukan belum dilakukan secara optimal.

Oleh karena itu, perlu dilakukan kajian pengelolaan limbah peternakan sapi Simantri berbasis 2R (Reduce dan Recycle) di Kecamatan Seririt, Kabupaten Buleleng. Penelitian ini bertujuan untuk menentukan laju timbulan dan komposisi limbah padat, mengevaluasi pengolahan limbah padat eksisting, dan menentukan strategi penerapan pengelolaan limbah padat berdasarkan hasil analisis SWOT (Strength, 
Weakness, Opportunity, dan Threats) pada peternakan sapi Simantri Kecamatan Seririt.

\section{URAIAN PENELITIAN}

\section{A. Persiapan Penelitian}

Pada persiapan penelitian dilakukan survei awal ke wilayah studi. Survei awal ini bertujuan untuk mengidentifikasi kondisi reaktor biogas dan pengomposan. Selanjutnya dilakukan penentuan lokasi penelitian yakni dengan memilih lokasi penelitian yang akan digunakan sebagai sampel yang representatif. Lokasi penelitian ini yakni pada Simantri Suka Jaya Makmur, Mayong Pengulkulan, Eka Santhi, Sari Mekar dan Madu Amerta. Selain itu, pada persiapan penelitian dilakukan perancangan kuisioner untuk memperoleh data pengelolaan limbah padat eksisting, permasalahan yang terjadi dan analisis SWOT. Kemudian dilakukan perijinan dan persiapan alat penelitian. Alat yang diperlukan dalam penelitian ini yaitu timbangan, karung plastik, sarung tangan, sekop, meteran, dan alat pengukur volume limbah padat $40 \mathrm{~L}$.

\section{B. Pengumpulan Data}

Pada penelitian ini dilakukan pengumpulan data berdasarkan aspek teknis dan aspek kelembagaan. Data yang diperlukan yaitu data primer dan sekunder. Data primer adalah data yang diperoleh dari hasil pengamatan secara langsung di lokasi. Sedangkan data sekunder merupakan data pendukung yang diperoleh dari instansi terkait.

Data primer yang diperlukan dalam penelitian ini, yaitu:

1) Pengukuran laju timbulan dan komposisi limbah padat Pada penentuan laju timbulan limbah padat peternakan akan di ukur jumlah limbah padat yang dihasilkan per hari pada tiap peternakan. Metode pengukuran sesuai dengan SNI 19-3964-1994.

2) Pengukuran luas lahan

Pada pengukuran luas lahan akan diukur luas lahan tiap peternakan sebagai data pendukung pengukuran laju timbulan limbah padat.

3) Mass balance limbah padat tiap peternakan

Pada perhitungan mass balance akan memperhatikan laju timbulan limbah padat per hari, jumlah limbah padat yang dimanfaatkan atau didaur ulang, jumlah produk dan residu yang dihasilkan dari pengolahan limbah padat. Perhitungan mass balance ini akan dilakukan di tiap lokasi penelitian.

4) Wawancara dan kuisioner tentang pengelolaan limbah padat eksisiting, permasalahan dan analisis SWOT.

Data sekunder yang diperlukan dalam penelitian ini, yaitu:

1) Peta wilayah studi

Peta wilayah studi diperlukan untuk mendapatkan informasi lokasi penelitian ini dilaksanakan.

2) Kapasitas anaerobik digester

Data kapasitas anaerobik digester diperlukan untuk mengetahui jumlah kotoran sapi yang dimasukkan tiap harinya.

3) Produktivitas kompos
Data produktivitas kompos diperlukan untuk mengetahui jumlah kompos yang dihasilkan tiap siklus pengomposan dan total kompos yang dihasilkan per tahun.

4) Fasilitas pengolahan biogas dan kompos

Data fasilitas pengolahan biogas dan kompos diperlukan untuk mendapatkan informasi fasilitas pengolahan biogas dan kompos yang terdapat dalam peternakan sapi Simantri.

\section{Analisis Aspek Teknis}

Analisis dari aspek ini dilakukan dari data yang dihasilkan dari pengukuran laju timbulan dan komposisi limbah padat, perhitungan mass balance, dan hasil tabulasi dari kuisioner. Selain itu, akan dibahas tentang pengelolaan limbah padat eksisting yakni penerapan teknologi pengolahan biogas dan kompos. Pada masing-masing peternakan akan dibahas tentang cara pembuatan biogas, jumlah bahan baku biogas, pemanfaatan biogas, kapasitas reaktor dan permasalahan penerapan teknologi biogas. Pada teknologi pengomposan akan dibahas tentang prosedur pembuatan kompos, bahan baku yang digunakan, kapasitas pengomposan, produktivitas pengomposan dan permasalahan dalam penerapan pembuatan kompos di masing-masing peternakan.

\section{Analisis Aspek Kelembagaan}

Analisis aspek kelembagaan ini dilakukan dengan menggunakan analisis SWOT. Analisis SWOT ini bertujuan untuk menentukan teknologi yang dapat diterapkan yang sesuai dengan faktor SWOT di peternakan tersebut. Analisis SWOT ini dilakukan pada teknologi pengolahan biogas dan kompos. Data hasil kuisioner tersebut dirumuskan 5-10 faktor strength (kekuatan), weakness (kelemahan), opportunity (peluang), dan threats (ancaman) dari masing-masing teknologi. Kemudian dibuat kuisioner untuk menentukan penilaian bobot dan rating berdasarkan masing-masing faktor tersebut. Dari hasil kuisioner penilaian bobot dan rating dilakukan perhitungan untuk menentukan bobot relatif dan skor. Perhitungan penentuan bobot relatif dan skor dilakukan berdasarkan faktor internal (S dan W) serta faktor eksternal (O dan T). Selanjutnya nilai faktor internal dan eksternal diplotkan ke diagram analisis SWOT [13]. Nilai x diperoleh dari selisih nilai total faktor internal, sedangkan nilai y diperoleh dari selisih nilai total faktor eksternal. Setelah diplot ke grafik maka dapat ditentukan strategi pengembangan yang akan dilakukan. Diagram analisis SWOT dapat dilihat pada Gambar 1. Faktor internal dan eksternal selanjutnya digunakan untuk merumuskan matriks SWOT. Pada matriks SWOT dirumuskan strategi yang diperoleh dengan menghubungkan faktor SO (strength - opportunity), ST (strength - threats), WO (weakness - opportunity), dan WT (weakness - threats). Matriks SWOT dapat dilihat pada Tabel 1.

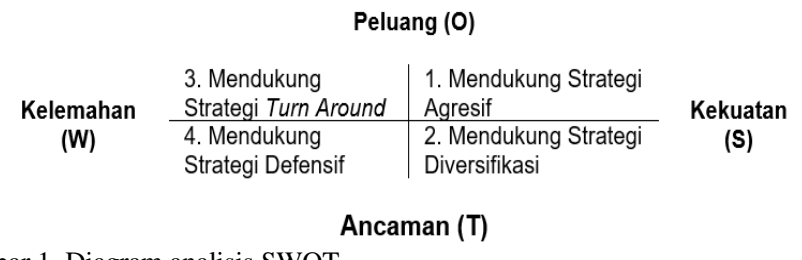

Gambar 1. Diagram analisis SWOT 
Tabel 1.

Matriks SWOT

\begin{tabular}{|c|c|c|}
\hline Faktor Internal & $\begin{array}{l}\text { Kekuatan }(S) \\
\text { - 5-10 faktor-faktor } \\
\text { kekuatan internal }\end{array}$ & $\begin{array}{l}\text { Kelemahan }(W) \\
\text { - 5-10 faktor-faktor } \\
\text { kelemahan } \\
\text { internal }\end{array}$ \\
\hline \multicolumn{3}{|l|}{ Faktor Eksternal } \\
\hline \multirow{4}{*}{$\begin{array}{l}\text { Peluang }(\mathrm{O}) \\
\text { - } 5-10 \text { faktor-faktor } \\
\text { peluang } \\
\text { eksternal }\end{array}$} & Strategi SO & Strategi WO \\
\hline & Ciptakan strategi & Ciptakan strategi \\
\hline & yang menggunakan & yang meminimalkan \\
\hline & $\begin{array}{l}\text { kekuatan untuk } \\
\text { memanfaatkan } \\
\text { peluang }\end{array}$ & $\begin{array}{l}\text { kelemahan untuk } \\
\text { memanfaatkan } \\
\text { peluang }\end{array}$ \\
\hline \multirow{4}{*}{$\begin{array}{l}\text { Ancaman }(T) \\
\text { - 5-10 faktor-faktor } \\
\text { ancaman } \\
\text { eksternal }\end{array}$} & Strategi ST & Strategi WT \\
\hline & Ciptakan strategi & Ciptakan strategi \\
\hline & yang menggunakan & yang meminimalkan \\
\hline & $\begin{array}{l}\text { kekuatan untuk } \\
\text { mengatasi ancaman }\end{array}$ & $\begin{array}{l}\text { kelemahan dan } \\
\text { menghindari ancaman }\end{array}$ \\
\hline
\end{tabular}

\section{HASIL DAN DISKUSI}

\section{A. Laju Timbulan dan Komposisi Limbah Padat}

Pengukuran laju timbulan dan komposisi limbah padat di peternakan sapi Simantri Kecamatan Seririt berdasarkan SNI 19-3964-1994 yang dilakukan selama 8 hari berturut-turut. Pengukuran ini dilakukan di Peternakan Sapi Simantri Suka Jaya Makmur, Mayong Pengulkulan, Eka Santhi, Sari Mekar, dan Madu Amerta. Pengukuran ini dilakukan mulai tanggal 24 Februari 2016 hingga 30 Maret 2016.

Pada Simantri Suka Jaya Makmur diperoleh rata-rata laju timbulan sisa pakan sebesar $1,38 \mathrm{~kg} / \mathrm{sapi}$.hari, sedangkan ratarata laju timbulan kotoran sapi sebesar 7,50 kg/sapi.hari. Sehingga rata-rata laju timbulan limbah padat total pada peternakan ini dihasilkan sebesar $8,88 \mathrm{~kg} / \mathrm{sapi}$.hari. Pada Simantri Mayong Pengulkulan rata-rata laju timbulan sisa pakan sebesar $1,00 \mathrm{~kg} / \mathrm{sapi}$.hari dan rata-rata laju timbulan kotoran sapi sebesar 7,37 kg/sapi.hari. Rata-rata laju timbulan limbah padat total pada peternakan ini dihasilkan sebesar 8,37 $\mathrm{kg} /$ sapi.hari. Pada Simantri Eka Santhi diperoleh rata-rata laju timbulan sisa pakan yaitu $0,94 \mathrm{~kg} / \mathrm{sapi}$.hari dan rata-rata laju timbulan kotoran sapi yaitu $7,10 \mathrm{~kg} / \mathrm{sapi}$.hari. Rata-rata laju timbulan limbah padat total pada peternakan ini dihasilkan yaitu 8,04 kg/sapi.hari. Pada Simantri Sari Mekar rata-rata laju timbulan sisa pakan sebesar $0,59 \mathrm{~kg} / \mathrm{sapi}$.hari dan rata-rata laju timbulan kotoran sapi sebesar 6,99 kg/sapi.hari. Rata-rata laju timbulan limbah padat total pada peternakan ini dihasilkan sebesar 7,58 kg/sapi.hari. Pada Simantri Madu Amerta diperoleh rata-rata laju timbulan sisa pakan sebesar 1,46 $\mathrm{kg} / \mathrm{sapi}$.hari dan rata-rata laju timbulan kotoran sapi sebesar $7,45 \mathrm{~kg} / \mathrm{sapi}$.hari. Rata-rata laju timbulan limbah padat total pada peternakan ini dihasilkan sebesar $8,91 \mathrm{~kg} /$ sapi.hari.

Simantri Suka Jaya Makmur dengan rata-rata laju timbulan kotoran sapi per ekor terbesar dari peternakan lainnya. Hal ini disebabkan, ukuran sapi pada peternakan ini lebih besar dibandingkan peternakan lainnya. Sedangkan, Simantri Madu Amerta menghasilkan rata-rata laju timbulan sisa pakan per ekor terbesar karena jumlah pakan yang diberikan tiap harinya lebih banyak dari peternakan lainnya. Simantri Sari Mekar dengan rata-rata laju timbulan sisa pakan dan kotoran sapi per ekor terkecil dari peternakan lainnya. Hal ini disebabkan, ukuran sapi, jumlah pakan dan frekuensi pakan pada peternakan ini lebih kecil dibandingkan peternakan lainnya. Grafik rata-rata laju timbulan dan komposisi limbah padat per ekor sapi dapat dilihat pada Gambar 2.

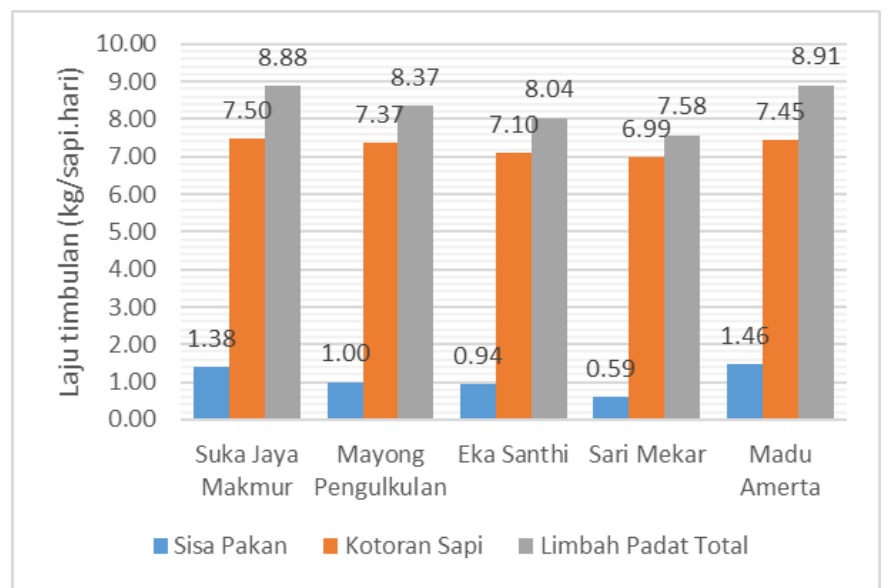

Gambar 2. Rata-rata laju timbulan dan komposisi limbah padat per ekor sapi pada 5 peternakan sapi Simantri

Berdasarkan dari hasil pengukuran pada 5 peternakan diperoleh rata-rata laju timbulan sisa pakan dan kotoran sapi yaitu $1,07 \mathrm{~kg} / \mathrm{sapi}$.hari dan $7,28 \mathrm{~kg} / \mathrm{sapi}$.hari. Data tersebut selanjutnya digunakan sebagai dasar perhitungan laju timbulan limbah padat total pada peternakan sapi Simantri Kecamatan Seririt. Hasil perhitungan laju timbulan dan komposisi limbah padat peternakan sapi Simantri Kecamatan Seririt dapat dilihat pada Tabel 2.

Tabel 2.

Hasil perhitungan laju timbulan dan komposisi limbah padat pada peternakan sapi simantri kecamatan seririt

\begin{tabular}{|c|c|c|c|c|c|}
\hline No & $\begin{array}{c}\text { Nama } \\
\text { Kelompok } \\
\text { Tani }\end{array}$ & $\begin{array}{c}\text { Jumlah } \\
\text { Sapi }\end{array}$ & $\begin{array}{c}\text { Laju } \\
\text { Timbulan } \\
\text { Sisa } \\
\text { Pakan } \\
\text { (kg/hari) }\end{array}$ & $\begin{array}{c}\text { Laju } \\
\text { Timbulan } \\
\text { Kotoran } \\
\text { Sapi } \\
\text { (kg/hari) }\end{array}$ & $\begin{array}{c}\text { Laju } \\
\text { Timbulan } \\
\text { Limbah } \\
\text { Padat } \\
\text { Total } \\
\text { (kg/hari) }\end{array}$ \\
\hline a & b & c & d & e & $\mathbf{f}=\mathbf{d}+\mathbf{e}$ \\
\hline 1 & $\begin{array}{l}\text { Amerta } \\
\text { Nadi }\end{array}$ & 7 & 7,49 & 50,96 & 58,45 \\
\hline 2 & $\begin{array}{l}\text { Puncak } \\
\text { Manik }\end{array}$ & 21 & 22,47 & 152,88 & 175,35 \\
\hline 3 & $\begin{array}{l}\text { Munduk } \\
\text { Sari }\end{array}$ & 21 & 22,47 & 152,88 & 175,35 \\
\hline 4 & $\begin{array}{l}\text { Werdhi } \\
\text { Nara Hita }\end{array}$ & 21 & 22,47 & 152,88 & 175,35 \\
\hline 5 & Eka Santhi & 28 & 29,96 & 203,84 & 233,8 \\
\hline 6 & $\begin{array}{l}\text { Tani } \\
\text { Mandiri }\end{array}$ & 23 & 24,61 & 167,44 & 192,05 \\
\hline 7 & Sari Mekar & 24 & 25,68 & 174,72 & 200,4 \\
\hline 8 & $\begin{array}{l}\text { Madu } \\
\text { Amerta }\end{array}$ & 23 & 24,61 & 167,44 & 192,05 \\
\hline 9 & $\begin{array}{l}\text { Suka Jaya } \\
\text { Makmur }\end{array}$ & 21 & 22,47 & 152,88 & 175,35 \\
\hline
\end{tabular}




\begin{tabular}{|c|c|c|c|c|c|}
\hline No & $\begin{array}{c}\text { Nama } \\
\text { Kelompok } \\
\text { Tani }\end{array}$ & $\begin{array}{c}\text { Jumlah } \\
\text { Sapi }\end{array}$ & $\begin{array}{c}\text { Laju } \\
\text { Timbulan } \\
\text { Sisa } \\
\text { Pakan } \\
\text { (kg/hari) }\end{array}$ & $\begin{array}{c}\text { Laju } \\
\text { Timbulan } \\
\text { Kotoran } \\
\text { Sapi } \\
\text { (kg/hari) }\end{array}$ & $\begin{array}{c}\text { Laju } \\
\text { Timbulan } \\
\text { Limbah } \\
\text { Padat } \\
\text { Total } \\
\text { (kg/hari) }\end{array}$ \\
\hline a & b & c & d & e & $\mathbf{f}=\mathbf{d}+\mathrm{e}$ \\
\hline 10 & $\begin{array}{l}\text { Bakti } \\
\text { Gopala }\end{array}$ & 24 & 25,68 & 174,72 & 200,4 \\
\hline 11 & $\begin{array}{l}\text { Madu } \\
\text { Merta } \\
\text { Mayong }\end{array}$ & 25 & 26,75 & 182 & 208,75 \\
\hline 12 & $\begin{array}{l}\text { Pengulkula } \\
\mathrm{n}\end{array}$ & 21 & 22,47 & 152,88 & 175,35 \\
\hline 13 & $\begin{array}{l}\text { Murdha } \\
\text { Sadhana }\end{array}$ & 25 & 26,75 & 182 & 208,75 \\
\hline \multicolumn{3}{|c|}{$\begin{array}{c}\text { Total Laju Timbulan } \\
\text { (kg/hari) }\end{array}$} & 303,88 & 2067,52 & 2371,40 \\
\hline
\end{tabular}

Laju timbulan sisa pakan $=1,07 \mathrm{~kg} /$ ekor.hari $\times$ jumlah sapi

Laju timbulan kotoran sapi $=7,28 \mathrm{~kg} / \mathrm{ekor}$.hari $\times$ jumlah sapi

Dari hasil perhitungan dari Tabel 2 diperoleh total laju timbulan sisa pakan dan kotoran sapi pada peternakan sapi Simantri Kecamatan Seririt yaitu 303,88 kg/hari dan 2067,52 $\mathrm{kg} /$ hari. Sehingga laju timbulan limbah padat total pada peternakan sapi Simantri Kecamatan Seririt berjumlah 2371,40 $\mathrm{kg} / \mathrm{hari}$.

\section{B. Teknologi Pengolahan Biogas}

Pada evaluasi kondisi teknologi pengolahan biogas, Simantri Suka Jaya Makmur dan Mayong Pengulkulan masih beroperasi teknologi pengolahan biogasnya. Sedangkan teknologi pengolahan biogas pada Simantri Eka Santhi, Sari Mekar dan Madu Amerta tidak beroperasi. Hasil pengukuran lama penggunaan kompor biogas pada Simantri Suka Jaya Makmur yaitu 1 jam 15 menit. Pada Simantri Mayong Pengulkulan menghasilkan lama penggunaan pada kompor biogas 1 jam 21 menit atau pada lampu biogas 1 jam 44 menit. Pada umumnya penyebab permasalahan biogas pada Simantri Eka Santhi, Sari Mekar dan Madu Amerta tidak beroperasi karena keterbatasan kapasitas pengolahan biogas, sarana dan prasarana biogas dalam kondisi yang kurang baik. Selain itu, adanya kendala distribusi biogas karena jarak dengan rumah penduduk sangat jauh dan kesulitan memperoleh sarana penunjang seperti kompor dan lampu biogas.

\section{Teknologi Pembuatan Kompos}

Pada saat evaluasi kondisi pembuatan kompos, Simantri Suka Jaya Makmur dan Eka Santhi masih melakukan pembuatan kompos. Sedangkan Simantri Mayong Pengulkulan, Madu Amerta dan Sari Mekar tidak melakukan pembuatan kompos. Produktivitas kompos pada Simantri Suka Jaya Makmur pada tahun 2015 yaitu 13,70 ton. Produktivitas kompos pada Simantri Eka Santhi pada tahun 2015 yaitu 76,16 ton. Kendala dalam pembuatan kompos ini yaitu tidak dapat dilakukan pembuatan kompos saat musim hujan. Hal ini karena bahan baku kompos yaitu jerami padi dan kotoran sapi perlu dilakukan penjemuran agar kadar air bahan baku kompos memenuhi. Pada umumnya penyebab permasalahan tidak dilakukan pembuatan kompos pada Simantri Mayong Pengulkulan, Sari Mekar dan Madu Amerta yakni kurangnya sarana pengomposan, kurangnya perencanaan dan keberlangsungan dalam pembuatan kompos, dan standar kualitas kompos belum diketahui. Selama ini limbah padat berupa kotoran sapi pada Simantri Sari Mekar dan Madu Amerta dijemur dan apabila sudah kering langsung dijual ke konsumen.

\section{Analisis SWOT}

Kuisioner SWOT pada penelitian ini diberikan ke masingmasing Ketua Simantri untuk dilakukan penilaian masingmasing faktor SWOT. Pada faktor kekuatan terdapat 5 faktor yang dirumuskan yaitu harga pupuk kompos relatif terjangkau, pengolahan biogas menghasilkan gas yang dapat digunakan untuk memasak dan penerangan. Selain itu, kemampuan finansial dalam penerapan teknologi pengolahan biogas dan kompos memadai. Ketersediaan bahan baku untuk pengolahan biogas dan pembuatan kompos sangat mencukupi dan tingkat pemahaman tenaga kerja akan teknologi pengolahan biogas dan kompos baik. Pada faktor kelemahan terdapat 5 faktor yang dirumuskan yakni keterbatasan kapasitas pengolahan biogas, kurangnya perencanaan dan keberlangsungan dalam pembuatan kompos. Selain itu, standar kualitas kompos belum diketahui dan keterbatasan kemampuan pemasaran biogas. Pada faktor peluang terdapat 5 faktor yang dirumuskan yakni mendukung kebijakan pemerintah Bali Clean and Green, tingginya permintaan pupuk kompos, meningkatnya minat masyarakat tentang produk organik. Selain itu, adanya kemajuan perkembangan teknologi dan pengembangan produk alternatif penerangan. Pada faktor ancaman terdapat 5 faktor yang dirumuskan yaitu populasi sapi berkurang, penggunaan biogas belum umum dimasyarakat, dan adanya perubahan iklim. Selain itu, adanya perubahan kebijakan pemerintah dan keterbatasan dalam memperoleh sarana penunjang teknologi biogas seperti kompor dan lampu biogas.

Dari hasil penilaian bobot dan rating pada kuisioner diperoleh nilai skor faktor kekuatan sebesar 1,51; kelemahan sebesar 0,95; peluang sebesar 1,41; dan ancaman sebesar 1,20. Sehingga, total nilai faktor internal yaitu 2,47 dan total nilai faktor eksternal yaitu 2,61. Kemudian dari masing-masing faktor tersebut dibuat matriks SWOT untuk menentukan strategi penerapan teknologi pengolahan biogas dan pembuatan kompos. Matriks tersebut dapat dilihat pada Tabel 5.20. Dari data hasil perhitungan nilai faktor internal dan eksternal, ditentukan strategi pengembangan yang akan dilakukan pada penerapan teknologi biogas dan kompos. Faktor internal dalam hal ini berperan sebagai sumbu horizontal (x) dan faktor eksternal berperan sebagai sumbu vertikal (y). Nilai koordinat $\mathrm{x}$ merupakan selisih dari nilai faktor kekuatan dan nilai faktor kelemahan. Nilai koordinat $\mathrm{x}$ $=1,51-0,95=0,56$. Sedangkan nilai koordinat y merupakan selisih dari nilai faktor peluang dan nilai faktor kelemahan. Sehingga nilai koordinat $y=1,41-1,20=0,21$. Bila diplotkan ke diagram kartesius, posisi titik koordinat strategi 
pengembangan terdapat di kuadran I, yakni strategi agresif. Pada hal ini Simantri dapat menggunakan kekuatan untuk memanfaatkan peluang yang ada dalam penerapan teknologi pengolahan biogas dan kompos. Posisi koordinat strategi pengembangan analisis SWOT dapat dilihat pada Gambar 3.

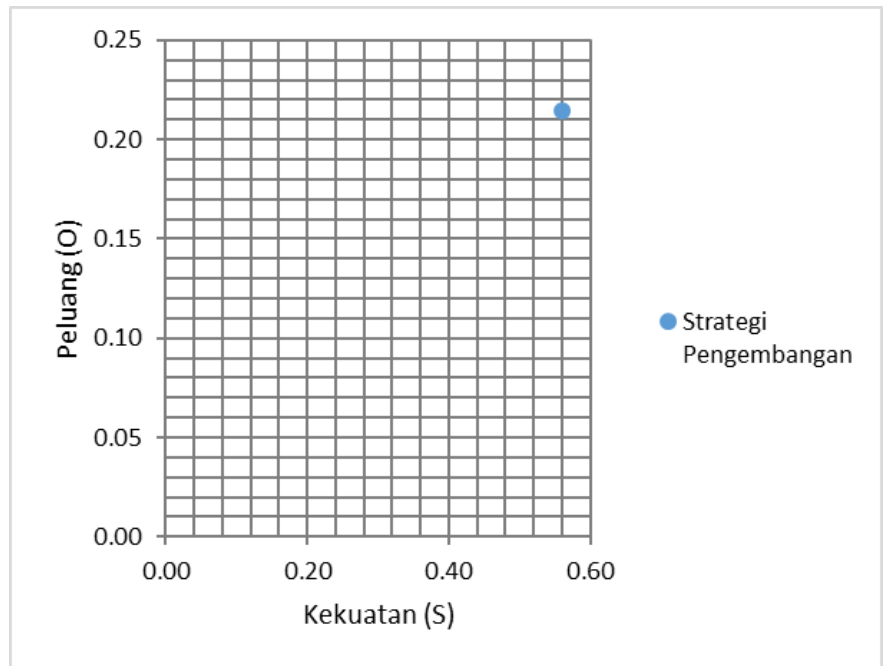

Gambar 3. Posisi Koordinat Strategi Pengembangan

Kemudian dari masing-masing faktor tersebut dibuat matriks SWOT untuk menentukan strategi penerapan teknologi pengolahan biogas dan pembuatan kompos. Matriks tersebut dapat dilihat pada Tabel 3.

Tabel 3.

Matriks Analisis SWOT Penerapan Teknologi Pengolahan Biogas dan Pembuatan Kompos

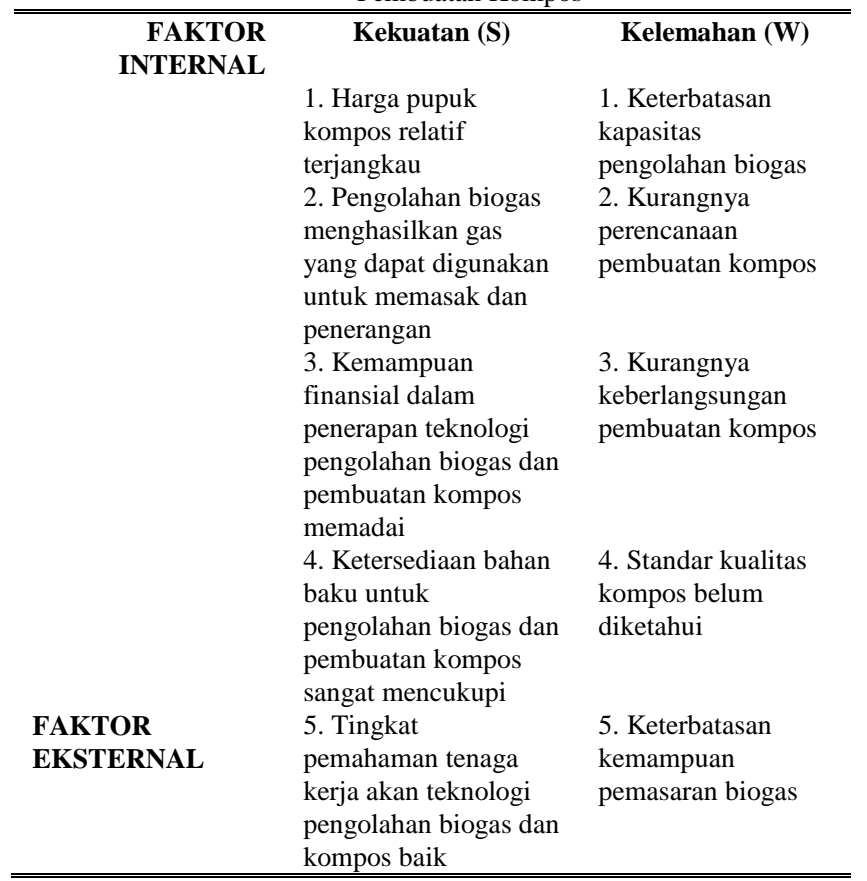

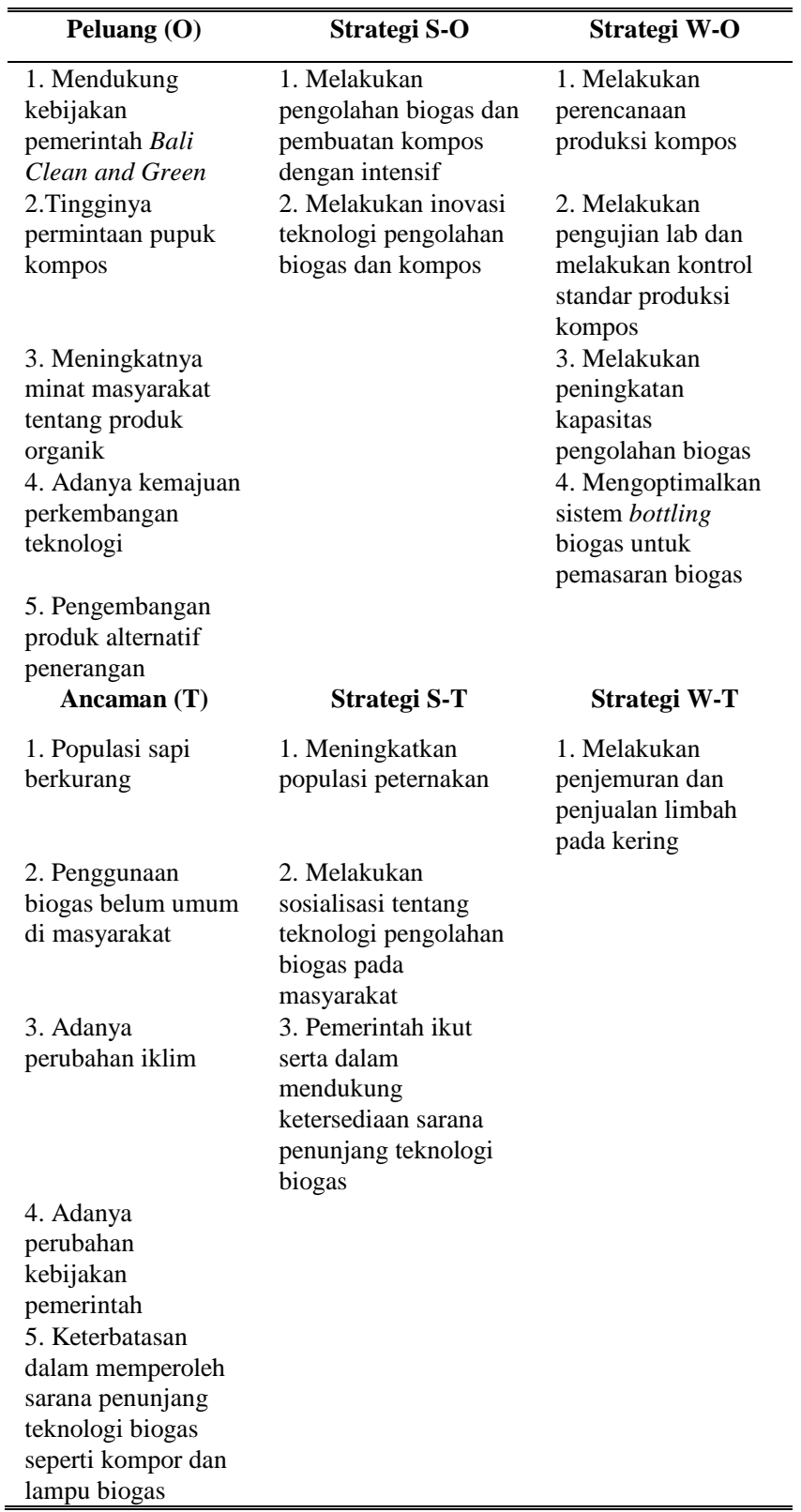

Berdasarkan hasil penempatan pada diagram kartesius yaitu posisi titik koordinat strategi pengembangan terdapat di kuadran I, yakni strategi agresif. Pada hal ini Simantri dapat menggunakan kekuatan untuk memanfaatkan peluang yang ada dalam penerapan teknologi pengolahan biogas dan kompos. Sehingga strategi yang akan dilakukan yakni melakukan pengolahan biogas dan kompos dengan intensif dan melakukan inovasi teknologi dalam pengolahan biogas dan pembuatan kompos.

\section{KESIMPULAN}

Kesimpulan yang diperoleh dari penelitian ini, yaitu: total laju timbulan sisa pakan dan kotoran sapi pada peternakan sapi Simantri Kecamatan Seririt yaitu 303,88 kg/hari dan 2067,52 $\mathrm{kg} / \mathrm{hari}$. Sehingga laju timbulan limbah padat total pada peternakan sapi Simantri Kecamatan Seririt berjumlah 2371,40 
kg/hari. Peternakan Sapi Simantri Kecamatan Seririt yang masih melakukan pengelolaan limbah padat sebanyak 53,84\% atau 7 peternakan. Sedangkan, yang tidak melakukan pengelolaan limbah padat sebanyak $46,16 \%$ atau 6 peternakan. Strategi penerapan teknologi untuk pengolahan limbah padat peternakan dari hasil analisis SWOT yaitu dengan melakukan pengolahan biogas dan pembuatan kompos dengan intensif dan melakukan inovasi dalam teknologi pengolahan biogas dan kompos.

\section{UCAPAN TERIMA KASIH}

Penulis mengucapkan terima kasih kepada Balai Penyuluhan Pertanian (BPP) Kecamatan Seririt dan Ketua Simantri Suka Jaya Makmur, Mayong Pengulkulan, Eka Santhi, Sari Mekar, dan Madu Amerta yang telah memberikan izin dan informasi pada pelaksanaan penelitian di Simantri Kecamatan Seririt.

\section{DAFTAR PUSTAKA}

[1] Winarti, E., dan Supriadi, "Usaha Perbibitan Sapi Potong Ramah Lingkungan (Studi Kasus Kelompok Peternak Ngudimulyo, Pleret, Bantul)," Prosiding Ekspose dan Seminar Nasional Inovasi Pertanian Ramah Lingkungan Makassar (2013).

[2] Mulyono, D, "Pemanfaatan Kotoran Ternak Sebagai Sumber Energi Alternatif dan Peningkatan Sanitasi Lingkungan," Jurnal Teknologi Lingkungan, Vol. 1, No. 1 (2000) 27-32.

[3] Haryati, T, "Biogas: Limbah Peternakan yang Menjadi Sumber Energi Alternatif," Wartazoa, Vol. 16, No. 3 (2006).

[4] Sulaeman. D., W. Palupi, M. Arif, H. Ungilia, E. Yuliarti, dan E. Listiawati, Profil Pengembangan Bio-Energi Perdesaan (Biogas), Jakarta, Direktorat Pengolahan Hasil Pertanian, Ditjen Pengolahan dan Pemasaran Hasil Pertanian, Departemen Pertanian (2009).

[5] Jorgensen, P. J, Biogas-Green Energy, Digisource Danmark A/S (2009).

[6] Al Seadi, T, Good Practice in Quality Management of AD Residues from Biogas Production, Denmark, University of Southern Denmark Esbjerg (2001).

[7] Prihandini, P. W. dan T. Purwanto, Petunjuk Teknis Pembuatan Kompos Berbahan Kotoran Sapi, Grati, Pusat Penelitian dan Pengembangan Ternak (2007).

[8] Sorathiya, L. M., A. B. Fulsoundar, K. K. Tyagi, M. D. Patel, dan R. R. Singh, "Eco-Friendly and Modern Methods of Livestock Waste Recycling For Enhancing Farm Profitability," International Journal Recycle Organic Waste Agriculture, Vol. 3, No. 50 DOI 10.1007/s40093-014-0050-6.. (2014).

[9] Christian, A. H., G. K. Evanylo, dan J. W. Pease, On-Farm Composting A Guide to Principles, Planning \& Operations, U.S. Virginia Cooperative Extension (2009).

[10] Cooperband, L, The Art and Science of Composting, U.S, University of Wisconsin-Madison (2002).

[11] Biro Humas Setda Provinsi Bali, Simantri Bangkitkan Pertanian Mепији Bali Organik, (2012) <URL:http://www.birohumas. baliprov.go.id/index.php/fasilitas/16/SIMANTRI> diakses tanggal 15 Oktober 2015.

[12] Dinas Pertanian Tanaman Pangan Provinsi Bali, Petunjuk Teknis Simantri, (2012) <URL:http://distanprovinsibali.com/ petunjuk- teknissimantri/> diakses tanggal 15 Oktober 2015 ..

[13] Rangkuti, F. Analisis SWOT Teknik Membedah Kasus Bisnis, Jakarta, PT Gramedia Pustaka Utama (2015). 